\title{
An Examination of Legislative Roll-Call Voting in the Czech Republic Using Spatial Models*
}

\author{
PAT LYONS and TOMÁŠ LACINA** \\ Institute of Sociology AS CR, Prague
}

\begin{abstract}
It is not clear from previous research if influential spatial techniques for analysing roll-data used in the Houses of Congress in the United States are appropriate in European multiparty systems. This is because the results of spatial analyses of roll-call data from the United States are interpreted in terms of ideological preferences. Within Europe party discipline is also a central feature of legislator behaviour. Consequently, spatial models of roll call behaviour in European legislatures should be explained in terms of party cohesion and discipline. This means that the correct interpretation of spatial models of roll-call data in places such as the Czech Republic requires access to additional sources of empirical evidence such as parliamentary survey data in order to make valid and reliable inferences about what motivates legislative behaviour. Using roll-call and parliamentary survey data from the sixth legislature in the Czech Republic (2006-2008), this research demonstrates that spatial models of roll-call data are not readily explainable in terms of party cohesion and discipline. The difficulty of making a substantive interpretation of dimensions extracted suggests the use of spatial models of roll-call voting where party discipline is strong requires more theoretical and methodological work.
\end{abstract}

Keywords: roll-call voting, spatial models, legislative behaviour, Czech Republic

Sociologický časopis/Czech Sociological Review, 2009, Vol. 45, No. 6: 1155-1190

\section{Introduction}

Legislative roll-call behaviour is typically seen to be determined by two key factors - party cohesion and party discipline [Ozbudun 1970; Hazan 2003]. It seems reasonable to ask: which of these two factors is most important? This is a difficult

\footnotetext{
* An early version of this paper was presented at ECPR Workshop Panel No. 26 on 'The Institutional Design of Parliamentary Rules', Lisbon, Portugal, 14-19 April 2009. The authors are grateful to workshop participants for helpful comments and suggestions. In undertaking this research the authors gratefully acknowledges funding from the Grant Agency of the Czech Republic (Grant No. 407/07/1395).

** Direct all correspondence to: Pat Lyons, Department of Political Sociology, Institute of Sociology, Academy of Sciences of the Czech Republic, Jilská 1, 11000 Prague 1, Czech Republic, e-mail: pat.lyons@soc.cas.cz; Tomáš Lacina, Institute of Sociology, Academy of Sciences of the Czech Republic, Jilská 1, 11000 Prague 1, Czech Republic, e-mail: tomas. lacina@soc.cas.cz.
} 
question to answer because legislators typically vote using mixed motivations, where cohesion, discipline, and other factors all contribute to the roll-call divisions observed. Two requirements are necessary to disentangle the cohesion and discipline components of legislators' roll-call behaviour: first, a means of summarising thousands of roll-call data into measures that validly and reliably capture each legislator's vote choices and the divisions across roll calls; second, information on legislators' personal and party's policy positions, thus giving subjective measures of party cohesion and legislators' perceptions of party discipline.

One influential approach to summarising many thousands of roll-call votes undertaken in a legislature during its term of office is to employ a spatial model where both legislators and bills are represented in a low, typically two-dimensional space [see Poole and Rosenthal 1991, 1997: 11-21]. Some of the key advantages of spatial representations of legislative behaviour are: 1) visualisation of large complex data sets facilitates greater understanding; 2) the logic of spatial models has an intuitive meaning, where measures of closeness or proximity indicate both the preference orderings for individual parliamentarians and which legislators are most similar to each other on the basis of their voting record; and 3 ) there is an extensive literature on legislative behaviour derived from the spatial theories of voting, coalition formation, and party competition.

In the spatial model each legislator is assumed to have an 'ideal point' representing their most favoured policy outcome for a specific bill, and each roll call is denoted by a 'cut-line' (dividing all the legislators who voted 'yes' or 'no') in a two-dimensional space [Poole and Rosenthal 1997: 12, 18]. This two-dimensional space is typically interpreted in ideological terms such as liberal-conservative, left-right, etc. Within this article the focus will be on spatial representations of legislative (roll-call) behaviour. ${ }^{1}$

In spatial models of roll-call data, the ideal points of legislators and the cut-points for bills may be derived from a variety of statistical analyses such as Multidimensional Scaling, using either a classical frequentist approach or Bayesian simulation, and Optimal Classification [Poole and Rosenthal 1997; Jackman 2001; Poole 2005]. Each of these statistical methods constructs a spatial model (or map) of roll-call behaviour on the basis of different assumptions and estimation algorithms.

This article will focus on multidimensional scaling (W-NOMINATE and IDEAL) and optimal classification (OC) methods of analysing roll-call data using the most recent (sixth) legislature in the Czech Republic as a case study of a typical example of roll-call voting in a European multiparty parliamentary system. The key purpose of this research is to 1) explore the substantive interpretation of the dimensions derived from spatial models, and 2) compare the spatial modelling results obtained using different statistical methods.

\footnotetext{
${ }^{1}$ Alternative methods of analysing roll-call data include: Agreement scores, Principal Components Analysis, and more recently Social Network Analysis [Rice 1924: 187; Heckman and Snyder 1997; Porter et al. 2005; Waugh et al. 2009].
} 
Selecting the Czech Republic's lower Chamber of Deputies as a case study of legislative party cohesion and discipline is sensible for four main reasons. First, legislative politics in the Czech Republic have undergone a remarkable transformation from a pattern characterised as disorganised and chaotic in the early 1990s to having a current legislative system that is similar to that in Western Europe. Second, the Czech Republic's proportional electoral system with (semi) open party lists and dominance of left-right as the basis of party competition offer an important opportunity to study party cohesion and discipline in a 'young' parliamentary system. Third, in the Czech Republic all votes on legislation in the Chamber of Deputies are subject to roll calls and this data (in electronic format) is available for study. Fourth, the sixth legislature (2006-2010) is a Minimum Winning Coalition where left and right wing parties were evenly balanced in the lower chamber, thus providing the prospect of studying party cohesion and discipline where both factors have important consequences for government stability.

The argument presented in this article is structured as follows. In the first section there is an overview of two theoretical explanations of roll-call behaviour which focuses on the importance of party cohesion and discipline. The second section, on data and methods, introduces the attitudinal and behavioural evidence examined in this article and the main spatial models used in the legislative studies literature to analyse roll-call behaviour. In the penultimate section there is a discussion of the empirical results; and this is followed by some concluding remarks and suggested avenues for future research.

\section{Spatial modelling of legislative behaviour}

Ozbudun [1970] was one of the first scholars to highlight the analytical and empirical confusion between the terms party 'cohesion' and party 'discipline.' According to Ozbudun [1970: 305], cohesion is defined as 'the extent to which, in a given situation, group members can be observed to work together for the group's goal in one and the same way'. In contrast, discipline was seen to refer either to 'a special type of cohesion achieved by enforcing obedience or to a system of sanctions by which such enforced cohesion is attained'. Despite Ozbudun's explicit goal of conceptual clarity he was not always successful in clearly differentiating between these two concepts.

In short, Ozbudun recognised that party cohesion and discipline are different facets of observed legislative behaviour where it is empirically difficult to estimate the separate effect of both factors. In this article, three spatial modelling strategies will be used to explore the party cohesion and discipline components of legislative voting in a typical European multiparty parliament, i.e. the Czech Republic's lower chamber called Poslanecká sněmovna, hereafter the Chamber of Deputies. Previous research on the Houses of Congress in the United States has most often interpreted the two-dimensional maps of legislative behaviour con- 
structed from roll-call data over two centuries (1789- ) in terms of ideology (liberal-conservative and race). Adopting issue positions that are defined in terms of being liberal, conservative, and race-related have been the primary criteria used to differentiate between why legislators are Democrats or Republicans. Ideology is thus seen to be the basis of party cohesion.

The Houses of Congress are different to their parliamentary counterparts in Europe because the level of party discipline evident in the United States is lower, or at least constructed on different foundations [Wattenberg 1998; Cox and McCubbins 1993, 2005]. This has a very important implication in the interpretation of the dimensions of spatial models. This is because it means that the estimated ideal points of legislators in European parliaments are likely to contain a stronger party discipline component than that evident in the Houses of Congress. In short, legislators' ideal points are not translated directly into observed roll-call behaviour because of the influence of strategic behaviour and institutions.

\section{Sincere and strategic aspects of legislative voting}

One of the primary bases for membership of one political party rather than another is policy preferences. Therefore, a citizen joins the party that is closest to them in ideological or policy terms. By extension, the ideological foundations of party membership will be the basis for observed roll-call behaviour as all like-minded partisan legislators vote similarly, if not identically, much of the time. On the basis of this logic, party cohesion determines legislative voting because roll-call vote choices represent the sincere preferences of the legislators. Consequently, in any spatial model of roll-call voting one would expect the first dimension (D.1) to be determined on an observable feature of party cohesion such as ideological orientation. This expectation is indicated by the central black arrow at the centre of Figure 1. This represents a purely policy-driven account of legislative voting where legislators and their Parliamentary Party Grouping (hereafter, PPG) vote sincerely on each issue on the basis of their general ideological orientation.

In the real world of parliamentary politics, legislators within the same PPG do not have the same ideal points and there are always selective incentives to compromise through log-rolling, where key policy priorities are attained at the expense of less important issues. These selective incentives are represented by the white arrow and D.3 at the top of Figure 1. In addition, institutions such as party organisations influence the translation of legislator and PPG ideal points into roll-call voting outcomes through factors such as a) the social norm of following the party line even if one disagrees with the party leadership's decisions; and b) fear of being disciplined by the party for non-compliance with instructions. Here party leaders may decide for strategic reasons to vote against a bill they most prefer in order to secure a roll-call victory against opponents, or on the basis of a log-rolling agreement made by different PPG leaders. 
Figure 1. Impact of selective incentives and institutions on the translation of party cohesion into legislative roll call voting

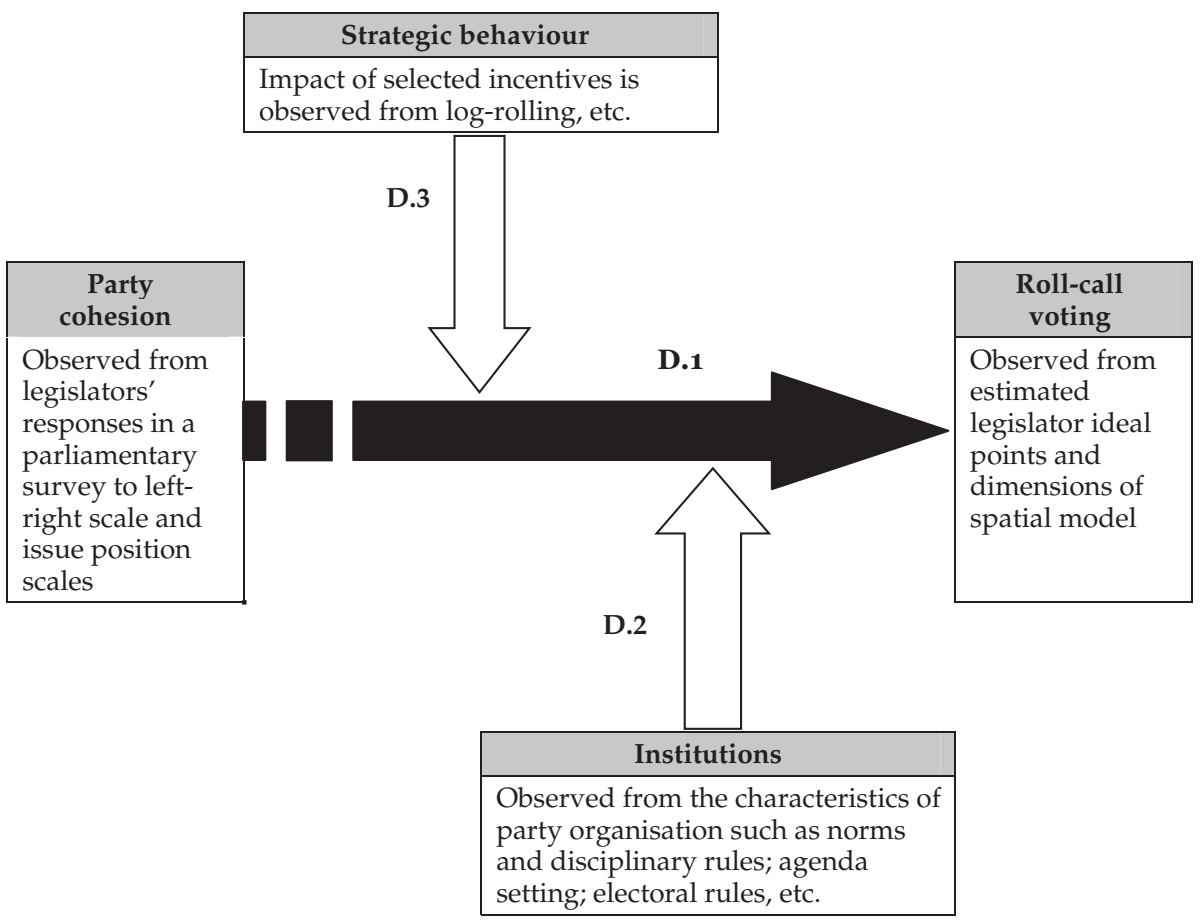

Notes: The logic represented in this figure is that roll call voting in the presence of complete party cohesion will represent a perfect translation of legislators' ideal points onto vote choice on bills. The labels 'D.1' and 'D.2' denote the two-dimensional components that should be observed in spatial representations of roll call voting, i.e. party cohesion (D.1) and party discipline (D.2) respectively. The third dimension (D.3) is assumed to reside in the party leadership where log-rolling is agreed among party leaders and not among individual legislators; thus becomes enveloped in the party cohesion and institutional determinants of roll-call vote choice.

Source: Hix and Noury [2008: 23].

\section{Dimensionality of the spatial model}

The dimensionality of the space employed in a spatial analysis is of critical importance in the substantive interpretation of the modelling results. Here there are two key considerations: the number of dimensions and substantive interpretation. The legislative studies literature suggests that political spaces derived from spatial models are dependent on a number of institutional features of a political system. For example, if a legislature is bicameral then ceteris paribus the spatial model should be uni-dimensional [Tsebelis and Money 1997]. The type of elec- 
toral system is also important. Proportional electoral rules will yield a greater number of dimensions than majoritarian ones. Closely related to electoral rules are district magnitude and the number of parties, where there will be a smaller number of dimensions with larger district magnitudes and smaller numbers of parties [Taagepera 1999, 2007]. Consequently, in the Czech Republic one would expect from previous research that legislative competition will be contained within a two-dimensional space.

Turning now to the question of the substantive interpretation of a two-dimensional space in a parliamentary system, Hix and Noury [2008] contend that in proportional electoral systems the main dimension will be left-right. However, coalition governments in proportional electoral systems must also take account of the fact that agenda-setting is more complicated. This is because it is more difficult to restrict the set of issues that come before the legislature. Consequently, roll-call voting will be determined by both the sincere policy preferences of legislators and strategic 'government vs. opposition' office-driven motivations.

On the basis of these theoretical considerations it is reasonable to propose two hypotheses regarding the nature of the political space in the sixth legislature of the Czech Republic (2006-2008). The first hypothesis reflects on whether legislative voting is best represented by one or more dimensions. On this question there has been little research beyond the work of Noury and Mielcova [2005] and Hix and Noury [2008]. ${ }^{2}$ The second hypothesis considers the substantive interpretation of each dimension. Here the previous literature has two contrasting interpretations which will be examined using parliamentary survey data.

H.1 A two-dimensional model will be the most appropriate representation of roll-call voting in the Czech Republic's (lower) Chamber of Deputies.

H.2a The first dimension will reflect the left-right nature of party competition in the Czech Republic. The second dimension will reflect differences in party positions regarding European integration [Noury and Mielcova 2005].

H.2b The first dimension will reflect a government vs. opposition pattern that is explained in terms of party discipline. The second dimension will reflect differences in left-right between parties and these differences reveal one of the primary pillars of party cohesion [Hix and Noury 2008].

The second hypothesis highlights a central impediment to the use of spatial representations of roll-call data where the substantive meaning of the dimensions extracted is unclear. This problem is compounded by 'observational equivalence',

\footnotetext{
${ }^{2}$ For example, Miller, White and Heywood [1998] examined Czech legislators' political orientations as part of a five-country post-communist study in 1993. This study focused on four key values, namely, socialist, nationalist, liberal, and democratic, rather than ideology. See Linek [2005] for an overview of all legislative surveys undertaken in the Czech Republic between 1993 and 2005.
} 
where different behavioural mechanisms yield the same results. This study will attempt to address this key substantive question by using a recent parliamentary survey data set which facilitates empirically testing among rival interpretations.

Before proceeding to a discussion of the data and methods employed in this study, it is necessary to make a brief note about the legislature examined. Following the general election of June 2006, a centre-right coalition government was formed between the Civic Democratic Party (ODS), the Christian Democrats (KDU-ČSL) and the Green Party (SZ). This administration was a Minimum Winning Coalition which took a record 219 days to construct and depended on the support of two rebels (Miloš Melčak and Michal Pohanka) from the opposition Social Democratic Party (ČSSD). For these reasons, one would expect roll-call voting to be strongly determined by party cohesion and discipline. It is now appropriate to switch attention to the data and methodology that will be used to test these two hypotheses.

\section{Data and methodology}

The legislative roll-call data examined in this study were obtained from the official database of the Czech Chamber of Deputies for the period June 2006 to December 2008. This period represents a little more than half of a regular legislative term of four years. However, the incumbent coalition lost a confidence vote on 31 March 2009 and this led to the resignation of the government. Early elections were planned for October 2009, but were postponed to June 2010 for legal reasons. Consequently, the data analyses reported here are the roll calls of the sixth Czech legislative term prior to the installation of an interim technical government (8 May 2009-May 2010).

\section{Dependent variable}

In total 4739 roll calls were recorded during the thirty-one-month period observed. These records indicate if a legislator was present or absent from the chamber. If present, the official records indicate whether the legislator cast a 'yes' or 'no' vote or alternatively abstained (i.e. was present in the chamber but did not vote 'yes' or 'no'). Voting in the Czech Parliament is overwhelmingly public and official records facilitate examining the record of all legislators. The option of a secret vote is only used for specific tasks: a) the election of the Chairman and Deputy Chairman of the Lower Chamber; and b) when filling certain positions outside the Chamber of Deputies [Syllová et al. 2008]. A typical feature of the Chamber of Deputies is that it votes frequently on a wide range of topics [Linek and Rakušanová 2005]. In practice, this means that there are a significant number of votes relating to minor questions such as the holding of breaks during a daily session. Lop-sided roll calls where there are no significant ( $\leq 2.5$ percent) party 
divisions are excluded from the analyses reported. In addition, legislators who participate in very few roll calls $(\leq 25)$ are also not considered. ${ }^{3}$

Within this study the dependent variable is the variation in roll-call voting between a legislator and their PPG. This is operationalised as the absolute distance between a legislator's spatial model score (i.e. W-NOMINATE, IDEAL and OC) and the median score of all legislators in their PPG for each dimension. It was noted above that the official roll-call results in the Czech Republic's Chamber of Deputies are coded as: (1) yes, (2) no, (3) absent from the parliament, (4) present in the chamber but did not participate in the specific roll call, and (5) absent from the chamber with an official excuse (e.g. medical reason, away on an official parliament trip, etc.). As most roll-call votes are conducted using a simple majority rule, a legislator's decision to abstain is equivalent to voting 'no' because it increases the threshold that a 'yes' vote must reach to be successful. Therefore, categories 2 and 4 were coded as 'no', and 3 and 5 were denoted as 'missing'.

Most previous research on roll-call data in the Czech Republic and elsewhere in Europe has focused on the concept of 'party unity', and adopted a strong positivist methodological position by conceptualising loyal PPG voting as an observed variable operationalised through measures such as the Rice Index or Index of Cohesion [Linek and Rakušanová 2005; Borz 2009; Bowler, Farrell and Katz 1999; Owens 2003; Sieberer 2006; Carey 2007, 2008: 178, 184; Depauw and Martin 2009: 103-105]. In such work, it is assumed that party unity is directly observable from the roll-call data. Krehbiel [1993, 2000] has criticised such a conceptualisation because complete party unity may stem from either perfect party discipline or total convergence of policy preferences. These very different motivations may yield the same observed outcome. This observed variable perspective ignores the legislator's preferences. Such strong positivism is surprising because much of the legislative studies literature emphasises, as noted above, that party unity is the product of party cohesion and party discipline [Ozbudun 1970; Hazan 2003]. Such a perspective suggests that party unity is something that has a number of sources and is therefore best conceptualised as a latent variable that is manifested in variables that measure party cohesion and discipline. If roll-call data are not a perfect measure of party unity, and are assumed to be so, this will result in an

\footnotetext{
${ }^{3}$ These constraints result in 4442 roll calls being examined (297 are deleted from being 'lop sided') for 207 legislators (with one member being removed for participating in very few votes). The constraints apply to ideal point estimates based on W-NOMINATE and OC, but not to IDEAL.

${ }^{4}$ The importance of this issue is evident in Curini and Zucchini [2008], Landi and Pelizzo [2006, 2009] and Rosas and Shomer [2008]. Han [2007: 482] treats 'present but not voting' as absenteeism and is hence treated as missing data. This increases the standard errors of the ideal point estimates. On balance it would be best to consider legislator abstention as something that is between a 'yes' and 'no' vote. Modelling sincere and strategic abstentions for legislators is one possible means of handling this thorny issue in future work [Desposato 2005: 21-22, 2006].
} 
'errors-in-variables' problem, where regression model coefficients will be both biased and inconsistent [Jackman 2008: 133-139].

Consequently, within this study, roll-call vote data are assumed to be observed indicators of latent utilities where legislators support or oppose a bill that maximises this utility. This theory of legislative behaviour and what roll-call data represent fits neatly with the logic of a spatial model of legislative voting where legislators cast their roll-call votes so as to maximise their utility. Here utility is defined in terms of the distance between preferred bill-voting outcomes and alternatives. As noted above, preferred roll-call results are defined as an ideal point, which is located in a hypothetical Euclidean space. Formally, each vote is defined as a choice between supporting a proposal and retaining the status quo. It is assumed that legislator utilities are not directly observed, but are in fact latent utilities. Legislators' utilities are conceptualised as single peaked preferences that span across a range of policy positions where a legislator votes either 'yes' or 'no' depending on their ideal point. Each roll call results in random utilities where the difference between a legislator's ideal point and the actual outcome is specified by a loss function (typically this is Gaussian or quadratic). A spatial model may be operationalised as a probit model where the error term is specified to have a normal distribution. This is the basic statistical foundation used by the three methods for constructing a spatial estimate of legislator ideal points and roll-call cut-points (i.e. points which indicate when legislators will vote 'yes' or 'no').

A central question in spatial models is: what do the ideal points represent in multidimensional space? As noted above, it is hypothesised that a spatial representation of the roll-call data for the Chamber of Deputies (2006-2008) will contain two dimensions representing party cohesion and discipline. This implies that each legislator's ideal point in this two-dimensional space represents these two components. As these two components or dimensions are independent (or orthogonal), this results in two dependent variables representing the party cohesion and discipline facets of each legislator's roll-call behaviour. It is of course an empirical question as to whether this interpretation of the two-dimensional space and legislator's ideal points is correct. Here appropriate independent variables derived from a different data source, a parliamentary survey, will be used to test the two hypotheses outlined above.

\section{Independent variables}

In addition, to the roll-call behaviour of legislators there have been periodic face-to-face surveys of members of the Chamber of Deputies for all six legislatures since 1993. Only a small number of items have been asked in each wave of this cross-time parliamentary survey programme. In the most recent wave implemented in late 2007 and early 2008, there are a wide range of questions exploring legislators' perceptions of their role; level of contact with institutions, special interest groups and political advisors; the relationship between legislators and 
their electoral districts; legislators' and their PPGs' positions on a wide range $(n=15)$ of policy scales. In addition, there is an extensive range of socio-demographic background variables. Of most interest in this study are a set of questions that explore the nature of roll-call voting in terms of a) a legislator's perceptions of party norms of loyalty, and b) a legislator's evaluation of likely disciplinary measures in a variety of hypothetical situations.

This parliamentary survey sample had a response rate of $68 \%$, where a total of 135 deputies out of 200 were interviewed. This response rate represents in comparative terms a high level of cooperation for this form of elite interviewing. An examination of the partisan representativeness of the sample reveals that there was an over-representation of left-wing legislators (i.e. from ČSSD and KSČM, $1.5 \%$ and $3.3 \%$, respectively). However, the deviation from the actual partisan composition is insufficient to seriously bias the sample examined in this study. See Appendix I for details.

Survey-based measures of party cohesion are based on three types of variables. First, differences between a legislator and their PPG with regard to ideology are captured with left-right self-placement and party placement scales. Second, dissimilarities between a legislator and their party on salient policies are explored in a similar manner with differences between self-placement and party placement scales. ${ }^{5}$ Third, a measure of the extent to which a legislator adheres to social norms that promote cohesion by supporting the party's position in the parliament even if this conflicts with personal preferences. Details of the questions employed and scales constructed are given in Appendix II. Summary statistics are provided in Appendix III. In general, the three types of party cohesion measures used in this study capture legislator's perceptions of a sense of common values and purpose.

In contrast, a legislator's evaluation of party discipline refers to how intra-party differences are managed either through self-discipline evident in conformity or through sanctions imposed by the party leadership for non-compliance with whipping instructions. Conformity in this study is operationalised through respondents' answers to four hypothetical situations where a legislator could vote in a roll call on the basis of their 'own opinion' or in line with the 'parliamentary faction's resolution'. A legislator's evaluation of the system of discipline in their party was constructed from their own estimation of the probability of sanctions being imposed in four different scenarios. These roll-call scenarios varied on the basis of whether a PPG judged a specific roll call to be vitally important or not, and they provide a reasonable measure of when legislators think disciplinary sanctions will be imposed. Details of the questions used to measure party discipline are given in Appendix II.

\footnotetext{
5 These survey-based indicators should offer better measures of legislators' sense of cohesion with their PPG. This is because they reflect each respondent's subjective perception of difference rather than relying on imputations of difference based on expert data sets.
} 
To summarise, using a spatial logic and the specific coding of the independent variables, which is described in Appendix II, it is expected that deviation from the party line in roll call voting will be associated with positive coefficients for all issue scales; and negative parameters for party norms, conformity, and sanctions for defying party instructions.

Having briefly described the key variables that will be used in this study to test the two hypotheses outlined above, it is now appropriate to make some specific remarks concerning how a legislator's ideal points will be estimated. This is important because different estimation procedures can yield variation in the spatial maps constructed for a legislature. Before starting it is important to stress that estimates of legislator ideal points have no 'real' meaning. They are inferences based on statistical estimates of the parameters of a vote choice (probability) model that have been constructed to fit as closely as possible with observed roll-call results. The presentation of a legislator's ideal points and roll-call divisions (cut-points) in a low dimensional space is achieved through a process of data reduction. This abstraction, or simplification, of reality is only useful if it facilitates making meaningful substantive inferences about legislative behaviour.

\section{Frequentist MDS analysis of roll-call data}

The most influential multidimensional approach to roll-call analysis in political science has its origins in Converse's [1964] conceptualisation of ideology as belief systems with 'constraint'; and Riker and Ordeshook's [1973] spatial modelling of political decision-making. The central insight is that vote choices across many issues may be effectively represented in a one- or two-dimensional space. This is because these one or two 'fundamental' dimensions generate the multitude of 'individual' issue dimensions observed in roll-call voting [Poole and Rosenthal 1997; Poole 2005]. This has important implications for the study and interpretation of political development [McCarty, Poole and Rosenthal 2006; Everson, Valelly and Wiseman 2008].

Using a spatial model of voting, Poole and Rosenthal's [1997] W-NOMINATE method of analysing roll-call data represents both legislators and roll-call divisions in a one- or two-dimensional space (typically). ${ }^{6}$ For simplicity, if one

\footnotetext{
${ }^{6}$ The NOMINATE (nominal three-step estimation) method of roll-call analysis uses a parametric unfolding procedure for binary data. It comes in a variety of 'flavours'. The original generic NOMINATE algorithm was written and implemented in 1981-1982 in the FORTRAN programming language. This version was revised between 1986 and 1988 for implementation on a super-computer and evolved into dynamic or D-NOMINATE. This version estimates ideal points across many different legislatures. A static version for computers running Windows with an Intel processor was developed between 1991 and 1994 and is known as W-NOMINATE. It is used for estimating ideal points and roll-call divisions for single legislatures. DW-NOMINATE is a revised version of the D-NOMINATE algorithm
} 
thinks of a one-dimensional space that may be interpreted in ideological terms such as left-right, W-NOMINATE attempts to correctly order both legislators and bills from far left to extreme right. The definition of what is a 'correct' ordering of legislators and roll-call divisions is based on correctly classifying the observed ('yes' or 'no') roll-call votes of legislators. In short, the goal is to find the parameters of a spatial model that maximises the correct 'yes' or 'no' vote for each legislator. These parameters represent the legislator's ideal point or most preferred policy position (assuming the dimensions are interpreted to be ideological in nature). One disadvantage of this Optimal Classification is that it is not possible to identify roll-call outcomes and determine the accuracy of the procedure. In addition, this technique is impractical for spatial models with two or more dimensions. To surmount these problems, W-NOMINATE uses the same essential logic but estimates legislator ideal points and roll-call divisions in a different manner. Legislators are assumed to vote with error, and this error is used to estimate the roll-call divisions (or cut-points). In practice, the estimation algorithm proceeds in two steps. In the first step, an ordering of legislators is estimated along with a parameter indicating the degree to which a (probabilistic) spatial model of voting makes correct versus incorrect predictions (known as the 'signal-to-noise ratio'). This procedure is completed for all roll calls and yields the roll-call outcome coordinates. In the second step, the signal-to-noise ratio is re-estimated keeping legislators' ideal point coordinates fixed. Then legislator ideal points are re-estimated once more keeping the roll-call divisions and signal-to-noise ratio fixed. This process continues iteratively until the legislator's ideal point and roll-call cut-points settle down to their final values. Unlike Optimal Classification, the W-NOMINATE technique does not try to maximise the number of correct classifications of roll-call votes and divisions. In contrast, W-NOMINATE maximises the probabilities that the spatial voting model assigns to the observed votes, where the legislator's ideal points are as close as possible to the actual choice selected for each vote. The W-NOMINATE procedure has two important disadvantages: it does not estimate (unconditional) standard errors, and it takes no account of missing data during the estimation process for providing information, for example, on the standard error of ideal point estimates.

\section{Bayesian MDS analysis of roll-call data}

The W-NOMINATE technique treats legislator ideal points as having specific values where the parameters are unknown. Estimation of the spatial voting model parameters is undertaken using a maximum likelihood analysis of the sampling distribution. By repeatedly drawing samples from the data generating process

that is used for computers using the Windows operating system. For details, see Poole and Rosenthal [1997], Poole [2005], and Carroll et al. [2008]. More recently, W-NOMINATE has been implemented in the $\mathrm{R}$ statistical programming language [Poole et al. 2007]. This is the software version used in this study. 
under examination, a distributional profile of the ideal points is created. This sampling distribution is used to select the 'most likely' ideal point values. In contrast, the Bayesian approach used in IDEAL assumes the ideal points and spatial voting model parameters are random (i.e. not fixed), that is, conditioned by the observed roll-call data. Within the Bayesian approach any 'prior' information about the data generating process examined is combined with the data observed to help estimate the 'posterior distribution', which summarises the model parameters of interest [Clinton, Jackman and Rivers 2004: 357]. As there is often a large volume of roll-call data, the advantage of having a priori information in estimating a spatial voting model generally makes little difference to using a frequentist approach such as W-NOMINATE. A key advantage of using a Bayesian approach is the ease of estimating the large set of spatial voting models typically involved in a roll-call analysis. In this study the model estimate has more than fourteen thousand parameters $(n=14,631)$. One method of implementing roll-call data analysis using Bayesian simulation is IDEAL [Jackman 2001; Clinton, Jackman and Rivers 2004; Clinton and Jackman 2009].7 IDEAL uses a Markov Chain Monte Carlo (MCMC) algorithm to draw repeated samples of the spatial voting model's parameters from their probability density function. Unlike W-NOMINATE the MCMC method used by IDEAL employs a quadratic utility rather than a normal (Gaussian) utility function. ${ }^{8}$ This difference means that the likelihood of a legislator supporting an alternative increases monotonically as they adopt increasingly extreme ideological positions leading to a 'stretching' of the ideological dimension [Lewis and Poole 2004; Carroll et al. 2008]. As a result, IDEAL may yield estimates with greater and more realistic variation in ideal points than W-NOMINATE, because the latter artificially constrains extreme legislators to lie within a specific region (a unit circle). An additional advantage of IDEAL over W-NOMINATE is that the Bayesian methodology permits unconditional estimates of parameter uncertainty (standard errors). Moreover, the Bayesian modelling framework allows for endogenous factors to be included in the estimation of ideal points, providing a more flexible approach to legislative behaviour [Jackman 2001; Clinton and Jackman 2009].

\section{Optimal Classification (OC)}

An alternative means of analysing legislative voting is to construct a ranking of legislators that matches most closely with the roll-call patterns observed. It has one key advantage over parametric techniques such as W-NOMINATE in that it

\footnotetext{
7 IDEAL is implemented in the R statistical programming language. An alternative version of the Bayesian approach to roll call analysis that is similar to IDEAL is available in MCMCpack, which is also available within the R statistical computing environment [Martin, Quinn and Hee Park 2010].

${ }^{8}$ See Carroll et al. [2007] and Clinton and Jackman [2009] for a more extensive comparison of W-NOMINATE and IDEAL.
} 
makes no assumptions about the errors in voting [Rosenthal and Voeten 2004: 620]. Poole [2005: 49-59] proposed using a non-parametric unfolding technique where roll call behaviour consists of 'yes' and 'no' choices. This technique makes three key assumptions. First, the (policy) space in which legislators exercise choice is Euclidean where they vote sincerely for the alternative that is closest to their ideal point. Second, legislators' roll-call preferences may be represented as single peaked and symmetric. Third, the classification errors across both legislators and roll calls are independent and identically distributed. In simple terms, Poole's Optimal Classification (OC) procedure has two steps. In the first step, the objective is to find the optimal cut-points for all bills. A rank ordering of legislators is estimated iteratively to identify the cut-point separating those who vote 'yes' or 'no' for all bills. The cut-points are selected on the basis of maximising the correct classification of legislators' vote choices. This yields a rank ordering of legislators interspersed by cut-points representing the yes/no divisions for each bill. In the second step, the goal is to find the optimal ordering of legislators. Here the relative ordering of bills to the 'left' or 'right' of each other is varied so as to maximise the correct classification of each legislator's vote choices. The algorithm then switches back to step one and the cycle continues until the ranking of legislators and roll-call divisions reaches the 'final' optimal values. Spirling and McLean [2007] demonstrate that where roll-call voting is determined by strategic voting typical of government vs. opposition divisions, then the OC procedure will yield invalid results because its assumption of sincere voting is unfounded. More specifically, $\mathrm{OC}$ is problematic when a) more than half of all votes are strategic, b) strategic voting is not equally prevalent within government and opposition parties, c) party rebels are more centrist that the government, d) the incentive to vote strategically is stronger for government rebels than the opposition, and e) the legislation examined is not subject to discipline within the governing parties.

\section{Results of roll-call analyses}

A comparison of the three different methods of estimating legislator ideal points shown in Figure 2 reveals two important things. First, the three methods produce broadly similar clustered partisan maps as shown later in Figure 3. Second, there are not strong correlations across the three ideal point estimators for each dimension and across dimensions. In general, the W-NOMINATE and OC estimates are more similar to each other when compared to the correlations for the IDEAL algorithm estimates (see Appendix II for details). ${ }^{9}$

\footnotetext{
9 The model fit statistics for W-NOMINATE and OC are reasonable. The W-NOMINATE model correctly classified $88 \%$ of the legislators on the first dimension and $90 \%$ on the second. For OC these values were $94 \%$ and $96 \%$ respectively. With regard to the standard fit statistics for these two models, the estimates for W-NOMINATE for both dimensions are APRE=.54/.59; $\mathrm{GMP}=.70 / .74$; while for $\mathrm{OC}$ the fit statistics are $\mathrm{APRE}=.80 / .86$ and $\mathrm{GMP}=.82 / .88$.
} 
Figure 2. Comparison of legislators' ideal points scores using different methods for two dimensions

(a) First dimension

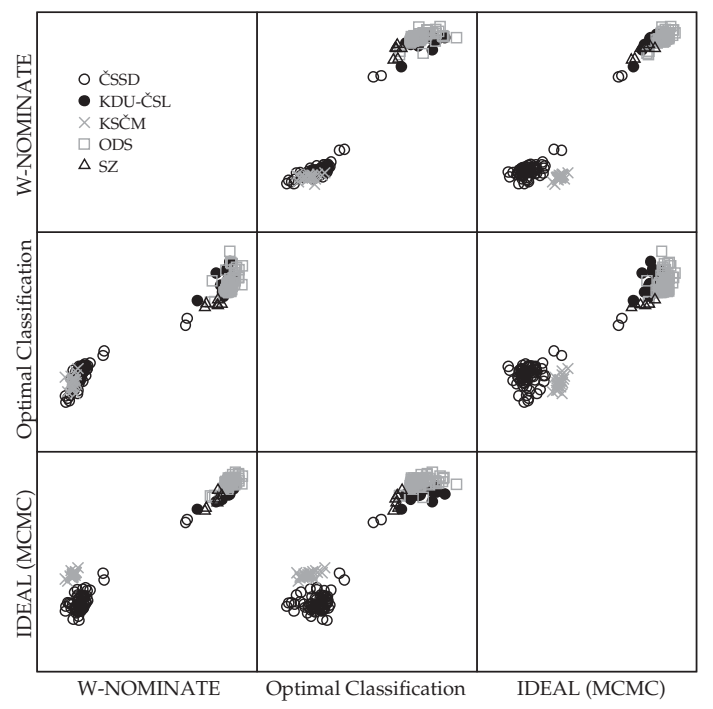

(b) Second dimension

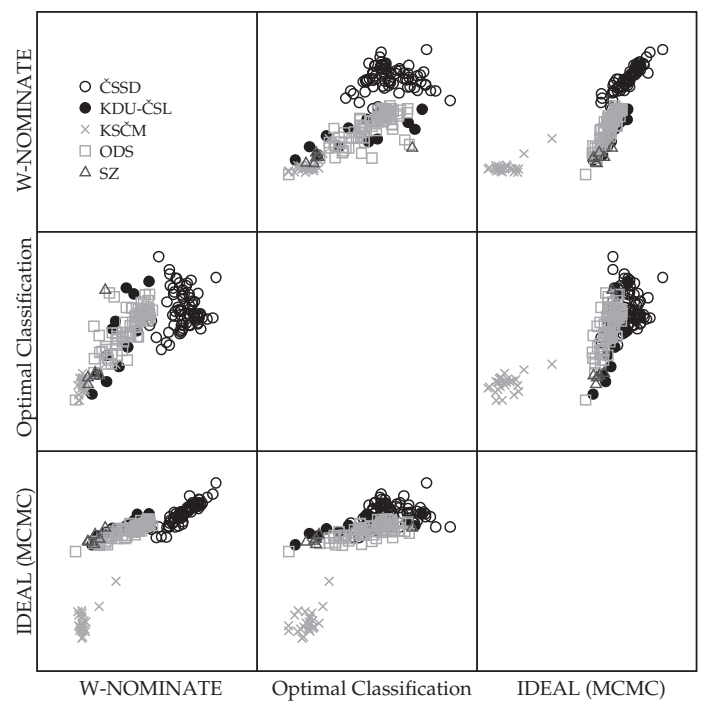

Source: Authors' calculations; Department of Informatics, Office of the Chamber of Deputies, Parliament of the Czech Republic. 
Window (a) of Figure 2 provides a comparison of the three methodologies for the first dimension estimated. These comparisons reveal that W-NOMINATE estimates for opposition parties (ČSSD and KSČM) have lower or less extreme values than that provided by the OC and IDEAL roll-call ideal point estimation techniques. This 'attenuating effect' may result from the fact that W-NOMINATE constrains extreme ideal point estimates to lie within a unit circle, thereby creating a 'ceiling effect'. The optimal classification (OC) method is unique in that this estimation technique maximises solely on the basis of correctly classifying the vote choices of legislators. By assuming perfect spatial voting, as is implied with an OC model of roll-call voting, this results in more centrist estimates along the first dimension than either the W-NOMINATE or the IDEAL techniques produce. As will be seen further on, this attenuating effect may be one facet of the greater variance evident in Figure 3 for all OC ideal point estimates.

Turning now to the second dimension represented by window (b) of Figure 2, it is immediately apparent that there are greater differences in the ideal points estimated using the three techniques. In general, the IDEAL estimates of legislator ideal points are greater (i.e. above the 'oblique' in each pane of Figure 2) than those given by W-NOMINATE or OC with the exception of KSČM. Such evidence suggests that specific features of the Bayesian approach to estimating ideal points become more important when generating the second dimension coordinates.

\section{Substantive interpretation of dimensions}

The dimensional (scree) plots from W-NOMINATE and OC (not reported) suggest that a two-dimensional solution was most appropriate. This confirms the first hypothesis and fits with previous roll-call analysis research on the Czech Republic's lower chamber using W-NOMINATE for the first four legislatures. According to Noury and Mielcova [2005] on the basis of a cross-time analysis from 1992 to 2002 the first dominant dimension evident during the period was left-right, and the second intermittent dimension was interpreted to relate to European integration. In contrast, Hix and Noury [2008] in a cross-national analysis suggest that in the fourth legislature [1998-2001] the dominant dimension was government vs. opposition and the second dimension was interpreted in terms of left-right ideology.

The results of all three roll-call analyses presented in windows $(\mathrm{a}-\mathrm{c})$ of Figure 3 for the sixth legislature show that the first dimension represents the broad left-right division of parties in the Czech Republic matching with Noury and Mielcova's [2005] findings. In more general terms, this dimension refers to a factor that provides Czech political parties with their main source of cohesion. This interpretation is not completely satisfactory as there is considerable overlap between parties on both sides of the left-right divide. With W-NOMINATE and OC there is no discrimination showing that KSČM is more leftist than ČSSD, or ODS 
Figure 3. Czech legislators' ideal positions in the sixth parliament using three different methods (2006-2008)

(a) W-NOMINATE scores

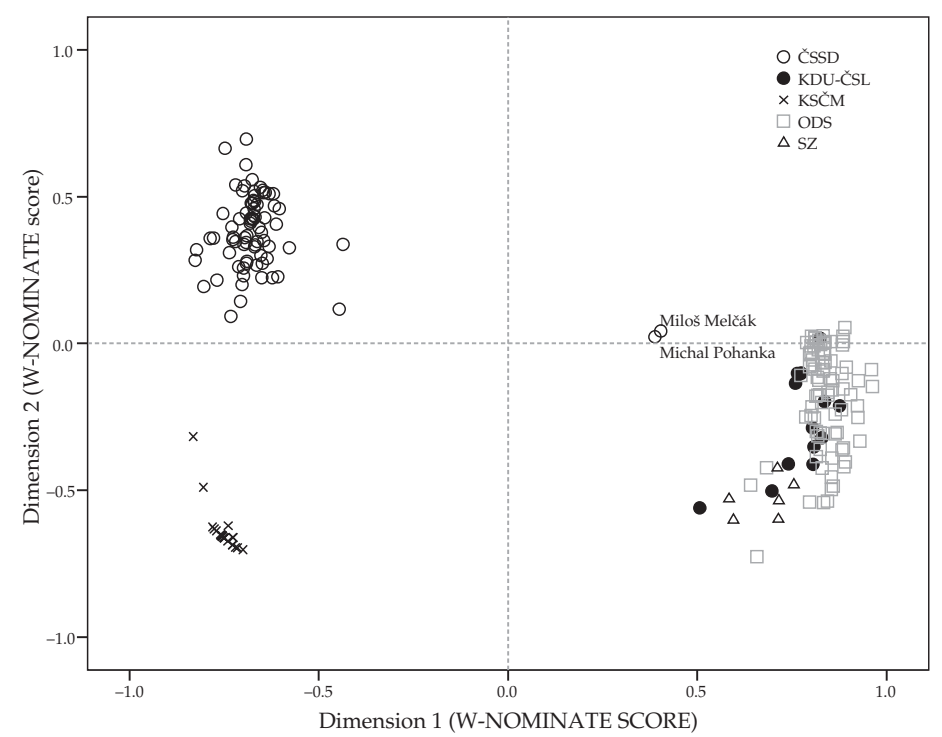

(b) Optimal Classification (OC) scores

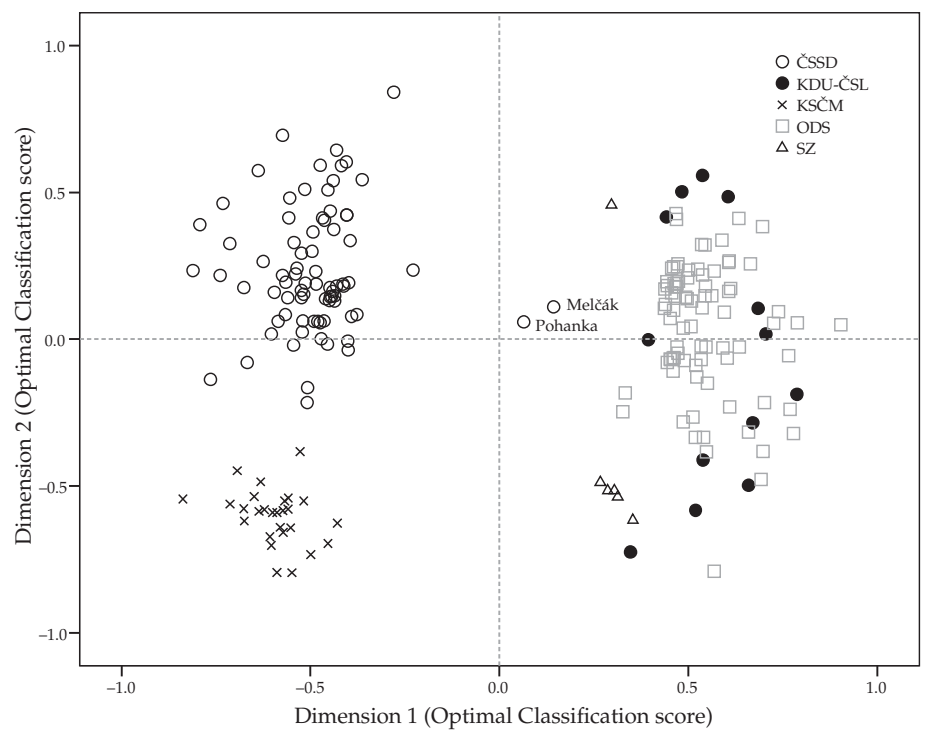


(c) IDEAL scores

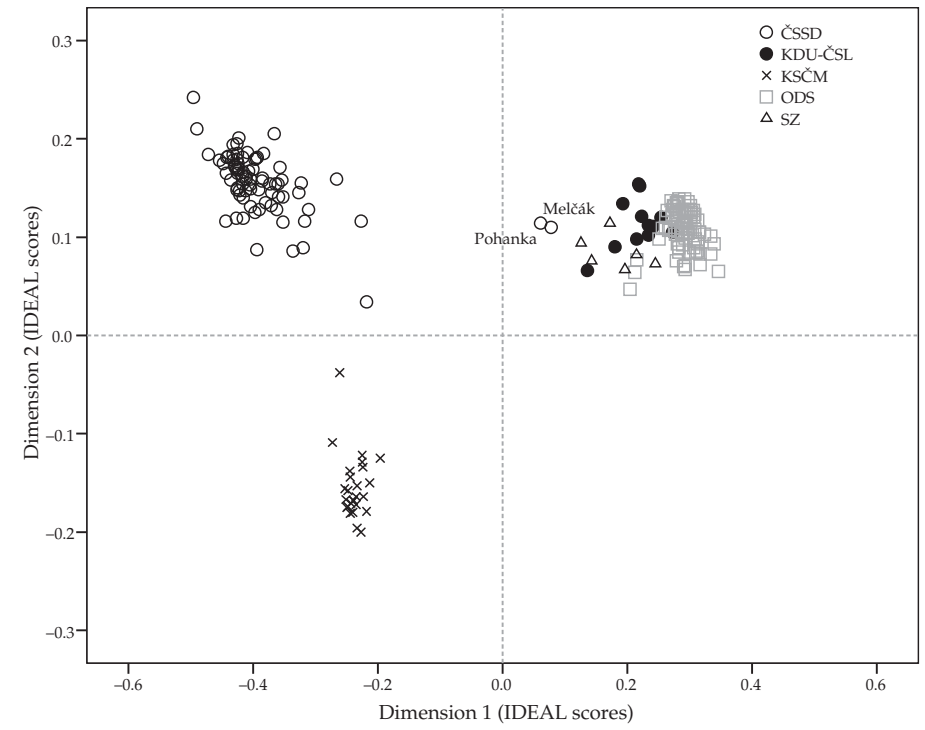

Notes: Unless stated otherwise, all estimates are based on coding legislators' absences from both the parliament and from specific votes, unless an official apology or excuse was recorded, as having voted 'no'. Miloš Melčak and Michal Pohanka are two rebel ČSSD legislators who supported the ODS-led government.

Source: Department of Informatics, Office of the Chamber of Deputies, Parliament of the Czech Republic.

is more to the right than KDU-ČSL and SZ. The IDEAL estimates shown in window (c) provide more inter-party differentiation on the first dimension, but suggest counter-intuitively that the Social Democrats (ČSSD) are more to the left than the Communists (KSCM). Notwithstanding these methodological differences in ideal point estimation, the left-right party division evident on the first dimension also matches Hix and Noury's [2008] government vs. opposition interpretation. Unfortunately, both the party cohesion and discipline mechanisms underpinning legislative voting yield observationally equivalent results. The only way to solve this inference problem is to employ additional information or data [Manski 1995]. This is the strategy followed in this study and will be described below.

Interpretation of the second dimension is even less straightforward. This stems in part from the fact that OC estimates of ideal points exhibit much larger intra-PPG variation than that evident in the W-NOMINATE and IDEAL coordinates. Here one can observe from windows (a-c) of Figure 3 that members of KSČM are at the lower (negative) end of this dimension while at the top (positive) end is ČSSD. The governing parties are in the centre (ODS, KDU-ČSL and SZ). According to Noury and Mielcova [2005] this pattern reflects differences in par- 
ty preferences toward European integration where the Social Democrats favour deeper integration most, the Communist Party least; and all right-wing parties tend to have intermediate pro-European positions.

An alternative interpretation is that the second dimension represents the government-opposition division within the Chamber of Deputies. Here the ODS-led coalition (with KDU-ČSL, SZ and two ČSSD rebels evident in the centre of each window of Figure 3) faces off against the government's main rival ČSSD (the second largest party) on the one hand and KSCM (the most ideologically different party) on the other. In general terms, this dimension may be interpreted as party discipline - an office-seeking motivation that binds the governing parties together against its two opponents. The opposition retain their independent positions vis-à-vis the government and themselves because they are not subject to the constraints of maintaining a majority in order to stay in office.

\section{Modelling legislators' ideal points as party cohesion and discipline}

In order to examine the substantive meaning of the two-dimensional spatial models of legislator ideal points estimated using W-NOMINATE, IDEAL and OC a series of Ordinary Least Squares (OLS) regression models explored each dimension in terms of party cohesion and discipline. The six dependent variables represent differences in roll voting between each legislator and the median PPG value. Examination of summary statistical estimates for each of these dependent variables revealed that they exhibit considerable skewness and kurtosis making them unsuitable for OLS regression. See Appendix III for details. Consequently, each dependent variable was transformed using a natural logarithm operator in order to correct for non-normality. This procedure was effective as the transformed summary statistics reveal much lower levels of skewness and kurtosis. A small number of control variables were also included in order to capture specific party effects, and to see if differences in legislators' political experience indicated by length of membership in the parliament (experience) and age were important. The results of this modelling exercise are presented in Table 1.

As noted earlier, the diagnostic estimates produced by W-NOMINATE and OC suggest that a two dimensional spatial map best represents the scaling analyses of the roll call data. This confirms the first hypothesis and is consonant with similar roll-call analyses of earlier legislatures [Noury and Mielcova 2005; Hix and Noury 2008]. With regard to the second hypothesis the results shown in Table 1 do not confirm the expectations outlined in Hypotheses $2 a$ or $2 b$. There is little evidence to support the view that dimension 1 refers to cohesion and dimension 2 measures party discipline. In fact, the model fit estimates presented in Figure 4 show that party cohesion and discipline explain a relatively small proportion of the total variation in five of the six dependent variables examined. In the sixth model (optimal classification, dimension 2) the dependent variable is 
Table 1. Regression models of legislators' roll-call behaviour in terms of party cohesion and discipline - part one

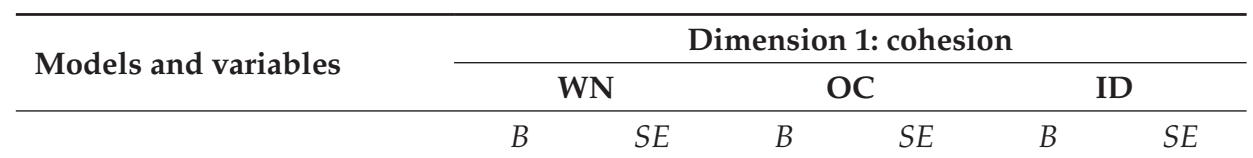

\section{Cohesion}

Left-right

European integration

$\begin{array}{rrrrrr}.18 & .16 & .45 & .15 & .02 & .14 \\ .03 & .10 & -.11 & .09 & .07 & .08 \\ .03 & .13 & -.22 & .13 & -.16 & .11 \\ -.26 & .10 & -.25 & .10 & -.04 & .09 \\ -.22 & .10 & -.04 & .10 & -.06 & .09 \\ .17 & .17 & .20 & .16 & .24 & .15 \\ .01 & .01 & .00 & .01 & .01 & .01\end{array}$

Health spending

Flat tax

Rent regulation

Intervention in economy

Party norms

$\begin{array}{rrrrrr}-.26 & .21 & -.28 & .20 & .02 & .18 \\ .17 & .14 & .37 & .13 & .12 & .12 \\ -.34 & .15 & -.43 & .14 & -.07 & .12 \\ .09 & .13 & .11 & .12 & .16 & .11 \\ -.21 & .11 & -.09 & .11 & -.18 & .10\end{array}$

Discipline

Conformity

Sanctions 1

Sanctions 2

Sanctions 3

Sanctions 4

$-.21$

.11

$-.09$

$-.18$

.10

Controls

Experience

$\begin{array}{rrrrrr}.00 & .16 & .20 & .15 & .20 & .14 \\ -.27 & .19 & -.11 & .18 & -.22 & .16 \\ \mathbf{1 . 9 6} & .95 & .00 & .90 & 1.27 & .82 \\ \mathbf{2 . 4 4} & \mathbf{1 . 0 8} & .49 & 1.02 & 1.24 & .92 \\ 1.49 & .95 & -.38 & .90 & .40 & .81 \\ \mathbf{1 . 8 8} & .98 & .03 & .92 & 1.11 & .83 \\ \mathbf{- 3 . 5 2} & \mathbf{1 . 7 0} & \mathbf{- 2 . 7 0} & \mathbf{1 . 6 1} & -\mathbf{5 . 8 5} & \mathbf{1 . 4 5} \\ .39 & & .40 & & .30 & \\ .19 & & .21 & & .06 & \\ 1.13 & & 1.07 & & .96 & \\ 1.94 & & 2.08 & & 1.28 & \\ .03 & & .02 & & .24 & \\ 74 & & 74 & & 74 & \end{array}$

Age

ČSSD

KDU-ČSL

KSČM

ODS

Intercept

R Square

Adj. R2

SE

F

Sig.

$\mathrm{N}$

74

74

2

$$
11
$$

Notes: Parameter estimates are based on an OLS regression model. The dependent variable is the natural logarithm of the distance between a legislator and the median position of their PPG. The grey shaded areas highlight parameters of the main theoretical interest. Coefficients in bold are significant $p<.10$. 
Table 1. Regression models of legislators' roll-call behaviour in terms of party cohesion and discipline - part two

\begin{tabular}{|c|c|c|c|c|c|c|}
\hline \multirow{3}{*}{ Models and variables } & \multicolumn{6}{|c|}{ Dimension 2: discipline } \\
\hline & \multicolumn{2}{|c|}{ WN } & \multicolumn{2}{|c|}{ OC } & \multicolumn{2}{|c|}{ ID } \\
\hline & $B$ & $S E$ & $B$ & $S E$ & $B$ & $S E$ \\
\hline \multicolumn{7}{|l|}{ Cohesion } \\
\hline Left-right & .201 & .167 & .004 & .081 & -.172 & .126 \\
\hline European integration & -.191 & .101 & -.021 & .049 & .127 & .076 \\
\hline Health spending & -.011 & .136 & -.004 & .066 & -.029 & .103 \\
\hline Flat tax & .094 & .107 & .016 & .052 & -.085 & .081 \\
\hline Rent regulation & -.096 & .108 & .031 & .053 & -.107 & .081 \\
\hline Intervention in economy & .183 & .176 & -.009 & .086 & .132 & .133 \\
\hline Party norms & .017 & .013 & -.004 & .006 & .013 & .010 \\
\hline \multicolumn{7}{|l|}{ Discipline } \\
\hline Conformity & -.259 & .214 & .009 & .104 & -.030 & .161 \\
\hline Sanctions 1 & -.091 & .142 & -.014 & .069 & .161 & .107 \\
\hline Sanctions 2 & -.109 & .150 & -.019 & .073 & -.170 & .113 \\
\hline Sanctions 3 & .202 & .134 & .039 & .065 & .190 & .101 \\
\hline Sanctions 4 & -.188 & .117 & .031 & .057 & -.001 & .088 \\
\hline \multicolumn{7}{|l|}{ Controls } \\
\hline Experience & .13 & .16 & .04 & .08 & .18 & .12 \\
\hline Age & -.23 & .20 & .00 & .10 & -.16 & .15 \\
\hline ČSSD & 3.80 & .98 & .89 & .48 & 2.05 & .74 \\
\hline KDU-ČSL & 4.21 & 1.11 & .77 & .54 & 1.90 & .84 \\
\hline KSČM & 2.74 & .97 & -3.03 & .47 & 1.78 & .73 \\
\hline ODS & 3.94 & 1.00 & .50 & .49 & 2.01 & .76 \\
\hline Intercept & -4.97 & 1.75 & -1.24 & .85 & -7.22 & 1.32 \\
\hline R Square & .53 & & .91 & & .33 & \\
\hline Adj. R2 & .38 & & .89 & & .10 & \\
\hline SE & 1.16 & & .57 & & .88 & \\
\hline $\mathrm{F}$ & 3.50 & & 32.22 & & 1.47 & \\
\hline Sig. & $\geq .01$ & & $\geq .01$ & & .14 & \\
\hline $\mathrm{N}$ & 74 & & 74 & & 74 & \\
\hline
\end{tabular}

Source: Department of Informatics, Office of the Chamber of Deputies, Parliament of the Czech Republic; Survey of the Members of the Chambers of Deputies, 2007/2008, Department of Political Sociology, Institute of Sociology, AS CR, Prague (authors' calculations). 
Figure 4. Overview of the explained variance for all OLS regression models

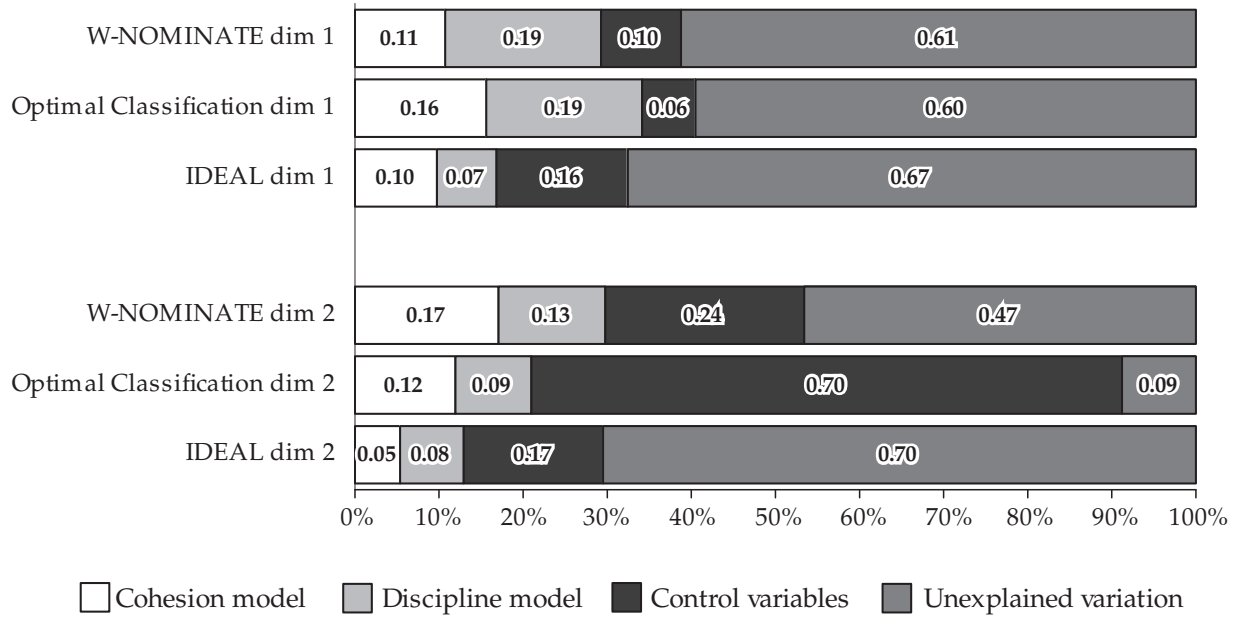

Notes: Estimates are based on hierarchical (OLS) regression models that are the same as those presented in Table 1 . The model fit estimates are ' $R$ square change' where the party cohesion model was estimated first, the party discipline model second, and the control variables model last. This procedure provides one means of evaluating the relative explanatory power for each of the three models (or block of variables) estimated. This figure should be interpreted as follows. For the W-NOMINATE model of dimension 1, 61\% of the total observed variance in the dependent variable is unexplained. Of the $39 \%$ of the total variance explained, $11 \%$ stemmed from the cohesion model, $19 \%$ from the party discipline model, and 10\% came from the control variables. For this dependent variable (W-NOMINATE dim 1) the party discipline model explains most variance. The very high level of explained variation in the Optimal Classification model for dimension 2 (91\%) is a methodological artefact stemming from the fact that the dependent variable exhibits a bimodal rather than unimodal profile.

Source: Department of Informatics, Office of the Chamber of Deputies, Parliament of the Czech Republic; Survey of the Members of the Chambers of Deputies, 2007/2008, Department of Political Sociology, Institute of Sociology AS CR, Prague.

problematic as it is bimodal rather than unimodal. This results in OLS estimation problems.

Moreover, for the first dimension party cohesion does not explain most variation as hypothesis 2a predicts; and party discipline does not explain most of the variance in the second dimension as hypothesis $2 b$ states. The evidence presented in Table 1 and Figure 4 demonstrates that the control variables and more specifically the party dummy indicators explain most observed variation. With the W-NOMINATE model for dimension 1 it seems that being a member of KDU-ČSL and to a lesser degree ČSSD and ODS is associated with higher levels of deviation from roll call loyalty. Expert commentary about divisions within the Christian Democrats led to the formation of a rightist splinter party called 
TOP 09 (Tradice Opovědnost Prosperita 09) on 11 June 2009. For this reason the parameters estimated make sense. However, in overall terms, contrary to our empirical and theoretical expectations the parliamentary survey based measures operationalising party cohesion and discipline have little power in explaining why Czech legislators do not always vote the party line.

Contrary to Noury and Mielcova [2005] the two dimensions evident in the W-NOMINATE, IDEAL and OC models do not strongly support an ideological interpretation. This is because differences between a legislator and their PPGs' median left-right and European integration positions are only evident in some models in Table 1, and these issue differentials have relatively little explanatory power as Figure 4 demonstrates. In general, there is little evidence to support the prediction expressed in hypotheses $2 \mathrm{a}$ and $2 \mathrm{~b}$ that the two dimensions in Figure 3 represent party cohesion and discipline.

A more detailed examination of the regression coefficients in Table 1 reveals inconsistencies (i.e. contrasting positive and negative parameters) across the models. The spatial logic of the regression model predicts that legislator deviation from the (median) party line in roll call voting will be explained by similar deviations from party positions on issues (cohesion) and discipline. In short, the model coefficients should have a positive sign where lack of cohesion helps to explain deviation from the party line in roll call voting, and a negative sign for the four sanctions variables (See Appendix II for details). The parameters presented in Table 1 show that the issue scales do not always have positive signs as the spatial logic would suggest. It seems that for some issues (health spending, flat taxes, and rent regulation) differences between a legislator and their PPG decrease defection on roll-call votes. Why this should be the case is not entirely clear. One might offer the conjecture that allowance of intra-party differences on non-salient issues fosters greater party unity. This is because legislators are given some freedom to express their views and work toward changing a party's official position, and in the meantime are expected to remain loyal to the party despite personal misgivings. Such a conjecture assumes that the issue variable parameters in Table 1 are not biased because of problems in the OLS regression model set-up. More will be said on this methodological point in the conclusion.

\section{Conclusion}

This study has presented the results of a spatial analysis of roll-call data for the Czech Republic's sixth legislature (2006-2008) using three of the most widely used methodologies. The central result of this empirical work is that the substantive interpretation of the dimensions extracted using a spatial modelling approach is problematic. Moreover, an attempt to deal with the observational equivalence problem (i.e. dimension 1 may reflect either left-right or government vs. opposition) evident in previous research by using additional parliamentary survey data 
has not been successful. The regression modelling results presented provide no clear interpretation of the two-dimensional maps estimated. Differences in regression model parameters across the three dependent variables operationalised for both dimensions demonstrates how multidimensional scaling maps are constructed has a determining effect on the legislator ideal points estimated and any inferences derived from such estimates.

The problems in making substantive interpretations of spatial representations of roll-call voting in parliamentary systems such as the Czech Republic provides a salutary lesson in the use of multidimensional and optimal scaling procedures for the analysis of roll-call data. The central lesson is that in parliaments where roll-call behaviour is determined by both legislators' preferences and party discipline spatial maps cannot be interpreted in purely ideological terms, as is the case with similar data from the Houses of Congress in the United States. In short, a key characteristic of roll-call behaviour in many European parliamentary legislatures is that legislators often do not vote for a piece of legislation that is closest to their ideal point as the spatial model of voting assumes.

Additionally if the W-NOMINATE, IDEAL or OC scores are measured with error, this has some important implications for making causal inferences using regression models. This is because roll-call scores derived from statistical algorithms such as W-NOMINATE are an example of an Estimated Dependent Variable (EDV). EDVs have by definition measurement error. Without getting into the details, failure to take account of measurement error runs the risk of regression models having inconsistent standard error estimates. Incorrect standard errors in turn undermine any attempt to make valid and reliable causal inferences [Lewis 2005].

Causal inference becomes even more fraught if there is correlation across the measurement errors among the independent variables [Achen 1985; Jackman 2008: 126-128]. This is likely if multiple measures of the same concept are used where for example issue scale responses are generally correlated with each other. In short, ignoring or misspecifying measurement error has the potential to lead to invalid inferences. This issue may lie behind the problems noted earlier with regard to the regression results shown in Table 1.

To conclude, use of spatial models of roll call voting to construct legislator ideal points represents an important opportunity to test formal models of legislator behaviour. However, where legislative behaviour is strongly determined by party discipline the evidence presented in this and other studies show that interpretation of the spatial dimensions becomes complicated by the fact that legislators' ideal points convey information about both preferences and discipline. Perhaps the use of survey data within the more flexible Bayesian approach to roll-call analysis represents a productive avenue for future theoretical and empirical work on roll-call voting in multiparty parliamentary legislatures. 
PAT LyONS is a senior researcher in the Department of Political Sociology at the Institute of Sociology of the Academy of Sciences of the Czech Republic. His main areas of research are public opinion, political attitudes, electoral and legislative behaviour, and party politics.

TOMÁš LaCina is a researcher in the Department of Political Sociology at the Institute of Sociology of the Academy of Sciences of the Czech Republic. His main research interest is legislative behaviour in the Czech parliament, and this is the subject of his doctoral research work.

\section{References}

Achen, C. H. 1985. 'Proxy Variables and Incorrect Signs on Regression Coefficients.' Political Methodology 11: 299-316.

Borz, G. 2009. 'Determinants of Party Unity in Europe: A Comparative Study of Parliamentary Parties in Twenty-three Countries.' PhD dissertation, Department of Political Science, Central European University, Budapest.

Bowler, S., D. M. Farrell and R. S. Katz. 1999. 'Party Cohesion, Party Discipline, and Parliaments.' Pp.3-22 in Party Discipline and Parliamentary Government, edited by S. Bowler, D. M. Farrell, and R. S. Katz. Columbus, OH: Ohio State University Press.

Carey, J. M. 2007. 'Principals, Political Institutions, and Party Unity in Legislative Voting.' American Journal of Political Science 51 (1): 92-107.

Carey, J. M. 2008. Legislative Voting and Accountability. New York: Cambridge University Press.

Carroll, R., J. B. Lewis, J. Lo, K. T. Poole and H. Rosenthal. 2008. ‘Comparing NOMINATE and IDEAL: Points of Difference and Monte Carlo Tests.' Legislative Studies Quarterly 34 (4): 555-591.

Clinton, J. D., S. Jackman and D. Rivers. 2004. 'The Statistical Analysis of Roll Call Data.' American Political Science Review 98 (2): 355-370.

Clinton, J. D. and S. Jackman. 2009. 'To Simulate or NOMINATE?' Legislative Studies Quarterly 34 (4): 593-621.

Converse, P. E. 1964. 'The Nature of Mass Belief Systems.' Pp. 206-261 in Ideology and Discontent, edited by D. E. Apter. New York: Free Press.

Cox, G. and M. D. McCubbins. 1993. Legislative Leviathan: Party Government in the House. Berkeley, CA: University of California Press.

Cox, G. and M. D. McCubbins. 2005. Setting the Agenda: Responsible Party Government in the US House of Representatives. New York: Cambridge University Press.

Curini, L. and F. Zucchini. 2008. 'Testing the Theories of Law Making in a Parliamentary Democracy: A Roll Call Analysis of the Italian Chamber of Deputies.' Paper presented at the ECPR Joint Sessions, Rennes, France.

Depauw, S. and S. Martin. 2009. 'Legislative Party Discipline and Cohesion in Comparative Perspective.' Pp. 103-120 in Intra-Party Politics and Coalition Governments, edited by D. Giannetti and K. Benoit. London: Routledge/ECPR Studies in European Political Science.

Desposato, S. W. 2005. 'The Impact of Party-Switching on Legislative Behavior in Brazil.' Unpublished paper, Department of Political Science, University of Arizona, USA. 
Desposato, S. W. 2006. 'Parties for Rent? Ambition, Ideology, and Party Switching in Brazil's Chamber of Deputies.' American Journal of Political Science 50 (1): 62-80.

Everson, P. R. Valelly and J. Wiseman. 2008. 'NOMINATE and American Political History: A Primer.' Unpublished paper. Retrieved 25 November 2009 (http://voteview.com).

Han, Hun J. 2007. 'Analysing Roll Calls of the European Parliament: A Bayesian Application.' European Union Politics 8: 479-511.

Hazan, R. Y. 2003. 'Does Cohesion Equal Discipline. Towards a Conceptual Delineation.' Journal of Legislative Studies (special issue on cohesion and discipline in legislatures) 9 (4): 1-11.

Heckman, J. and J. M. Synder. 1997. 'Linear Probability Models of the Demand for Attributes with an Empirical Application to Estimating the Preferences for Legislatures.' Rand Journal of Economics 28: S142-S189.

Hix, S. and A. Noury 2008. 'Government-Opposition or Left-Right? The institutional determinants of voting in fourteen parliaments.' Paper presented at the Annual Conference of the American Political Science Association, Chicago, Illinois.

Jackman, S. 2001. 'Multidimensional Analysis of Roll Call Data via Bayesian Simulation: Identification, Estimation, Inference, and Model Checking.' Political Analysis 9 (3): 227-241.

Jackman, S. 2008. 'Measurement.' Pp. 119-151 in The Oxford Handbook of Political Methodology, edited by J. Box-Steffensmeier, H. Brady and D. Collier. Oxford: Oxford University Press.

Krehbiel, K. 1993. 'Where's the Party?' British Journal of Political Science 23: 235-266.

Krehbiel, K. 2000. 'Party Discipline and Measures of Partisanship.' American Journal of Political Science 44 (2): 206-221.

Landi, M. and R. Pelizzo. 2006. 'A Spatial Analysis of the XIII Italian Legislature.' Paper presented at the Annual Midwest Political Science Association Meeting, Chicago, Illinois, USA.

Landi, M. and R. Pelizzo. 2009. 'A Spatial Analysis of the Italian Second Republic.' Unpublished Working Paper, Singapore Management University.

Lewis, J. B. and D. A. Linzer. 2005. 'Estimating Regression Models in which the Dependent Variable is based on Estimates.' Political Analysis 13 (4): 345-364.

Lewis, J. B. and K. T. Poole. 2004. 'Measuring Bias and Uncertainty in Ideal Point Estimates via Parametric Bootstrap.' Political Analysis 12 (2): 105-127.

Linek, L. 2005. 'Surveys of MPs and Senators in the Parliament of the Czech Republic between 1993 and 2005.' Sociologický časopis/Czech Sociological Review 41 (3): 487-497.

Linek, L. and P. Rakušanová. 2005. 'Why Czech Parliamentary Party Groups Vote Less Unitedly. The Role of Frequent Voting and Big Majorities in Passing Bills.' Sociologický časopis/Czech Sociological Review 41 (3): 423-442.

Manski, C. F. 1995. Identification Problems in the Social Sciences. New York: Cambridge University Press.

Martin, A. D., K. M. Quinn and J. Hee Park. 2010. 'MCMCpack: Markov Chain Monte Carlo in R.' Journal of Statistical Software (forthcoming).

McCarty, N., K. T. Poole and H. Rosenthal. 2006. Polarized America: The Dance of Ideology and Unequal Riches. Cambridge, MA: MIT Press.

Miller, W. L., S. White and P. Heywood. 1998. Values and Political Change in Postcommunist Europe. New York: St. Martin's.

Noury, A. and E. Mielcova. 2005. 'Electoral Performance and Voting Behaviour. Evidence from the Czech Parliament 1992-2002.' Center on Institutions and Governance Working Paper No.8, Institute of Government Studies, University of California, Berkeley, USA.

Owens, J. E. 2003. 'Explaining Party Cohesion and Discipline in Democratic Legislatures: Purposiveness and Contexts.' Journal of Legislative Studies 9 (4): 12-40. 
Ozbudun, E. 1970. Party Cohesion in Western Democracies: A Causal Analysis. SAGE Professional Papers in Comparative Politics. Beverly Hills, CA: Sage Books.

Poole, K. T. 2005. Spatial Models of Parliamentary Voting. New York: Cambridge University Press.

Poole, K. T. and H. Rosenthal. 1991. 'On Dimensionalizing Roll Call Votes in the US Congress.' American Political Science Review 85: 955-960.

Poole, K. T. and H. Rosenthal. 1997. Congress: A Political Economic History of Roll Call Voting. Oxford: Oxford University Press.

Poole, K. T., J. Lewis, J. Lo and R. Carroll. 2007. 'Scaling Roll Call Votes with W-NOMINATE in R.' Journal of Statistical Software (American Statistical Association) 22 (1): 1-21.

Porter, M. A., P. J. Mucha, M. E. J. Newman, and C. M. Warmbrand. 2005. 'A Network Analysis of Committees in the U.S. House of Representatives.' Proceedings of the National Academy of Sciences (PNAS) 102 (20): 7057-7062.

Rice, S. A. 1924. Farmers and Workers in American Politics. New York: Columbia University Press.

Riker, W.H. and P.C. Ordeshook. 1973. An Introduction to Positive Political Theory. Englewood Cliffs, NJ: Prentice Hall.

Rosas, G. and Y. Shomer. 2008. 'Non-ignorable Abstentions in Roll-call Data Analysis.' Unpublished paper, Washington University, St. Louis, Missouri, USA.

Rosenthal, H. and E. Voeten. 2004. 'Analyzing Roll Call Votes with Perfect Spatial Voting: France 1946-1958.' American Journal of Political Science 48: 620-632.

Sieberer, U. 2006. 'Party Unity in Parliamentary Democracies: A Comparative Analysis.' Journal of Legislative Studies 12 (2): 150-178.

Spirling, A. and I. McLean 2007. 'UK OC OK? Interpreting Optimal Classification scores for the U.K. House of Commons.' Political Analysis 15: 85-96.

Syllová, J., P. Kolář, J. Kysela, J. Georgiev and S. Pecháček. 2008. Parlament České republiky. (Parliament of the Czech Republic) Prague: Linde Praha a.s.

Taagepera, R. 1999. 'The Number of Parties as a Function of Heterogeneity and Electoral System.' Comparative Political Studies 32 (5): 531-548.

Taagepera, R. 2007. Predicting Party Sizes: The Logic of Simple Electoral Systems. Oxford: Oxford University Press.

Tsebelis, G. and J. Money. 1997. Bicameralism. New York: Cambridge University Press.

Wattenberg, M. 1998. The Decline of American Political Parties, 1952-1996. Cambridge, MA: Harvard University Press.

Waugh, A. S., L. Pei, J. H. Fowler, P. J. Mucha and M. A. Porter. 2009. 'Party Polarization in Congress: A Social Networks Approach.' Working Paper deposited at: arXiv:0907.3509v1 [physics.soc-ph], version July 20. 


\section{Appendix I}

The survey of members of the Chamber of Deputies (Poslanecká sněmovna) $(2007 / 8)$ is based on face-to-face interviews with legislators undertaken between 11 October 2007 and 21 February 2008 by a specially trained team of interviewers. There was a $68 \%$ response rate, i.e. 136 members were interviewed out of a total lower chamber membership of $200 \mathrm{MPs}$. In comparative terms, this is a high response rate where rates below one-in-two are common. Unsurprisingly, there was a differential response rate among MPs from the five parties represented in the Chamber of Deputies, as may be seen in the following table, where there was oversampling of leftist members from ČSSD and KSČM and under-sampling of rightist members from KDU-ČSL and ODS. Unsurprisingly, there is a size effect where MPs from the smaller parties, i.e. KDU-ČSL and SZ proved more difficult to interview.

Partisan profile of response rates in the Chamber of Deputies Survey (2007/8)

\begin{tabular}{|c|c|c|c|c|c|c|}
\hline \multirow[b]{2}{*}{ Party } & \multicolumn{2}{|c|}{ Actual } & \multicolumn{2}{|c|}{ Surveyed } & \multicolumn{2}{|c|}{ Difference } \\
\hline & Seats & $\%$ & Seats & $\%$ & $\%$ & Notes \\
\hline ČSSD & 74 & 37.0 & 52 & 38.2 & -1.52 & Oversampled \\
\hline KDU-ČSL & 13 & 6.5 & 7 & 5.1 & 1.31 & Undersampled \\
\hline KSČM & 26 & 13.0 & 22 & 16.2 & -3.30 & Oversampled \\
\hline ODS & 81 & 40.5 & 49 & 36.0 & 4.20 & Undersampled \\
\hline SZ & 6 & 3.0 & 3 & 2.2 & 0.78 & Undersampled \\
\hline Other & 0 & 0.0 & 2 & 1.4 & & \\
\hline Total & 200 & 100.0 & 136 & 100.0 & & \\
\hline
\end{tabular}

Notes: 'Other' refers to a) MPs who were elected for a specific party, but who at the time of interview had broken from their former Parliamentary Party Grouping or b) refused in the interview to state a party affiliation.

Source: Department of Informatics, Office of the Chamber of Deputies, Parliament of the Czech Republic and Survey of the Members of the Chambers of Deputies, 2007/2008, Department of Political Sociology, Institute of Sociology AS CR (authors' calculations). 


\section{Appendix II}

\section{Survey Items Measuring Czech Legislators' Perceptions of Party Cohesion and Discipline}

\section{Left-right self-placement}

Q.31. Political opinions can be oriented to left or right. How would you position following parties? a) ČSSD, b) KDU-ČSL, c) KSČM, d) ODS, e) SZ. Left is zero on this 11-point scale and 10 is right.

\section{Q.32 Where would you place yourself on this scale?}

Note that the difference in left-right position between each legislator and their party was estimated from the median scores for these two items. This may be said to yield a 'subjective' measure of left-right difference. An alternative approach is to subtract each legislator's median position from the median position of all members of their PPG. This may be interpreted as a more 'objective' indicator. In the analyses reported the subjective measure is used. However, additional analyses reveal that use of the objective operationalisation yields the same substantive results.

Q.36 We would like to know your attitude towards particular problems. How are your positions oriented? (First statement 0 , second statement 10)

Q.37a: In your opinion, what is the attitude of ČSSD on the following societal questions?

Q.37b: In your opinion, what is the attitude of KDU - ČSL on the following societal questions?

Q.37c: In your opinion, what is the attitude of KSČM on the following societal questions?

Q.37d: In your opinion, what is the attitude of ODS on the following societal questions?

Q.37e: In your opinion, what is the attitude of SZ on the following societal questions?

[a] Health spending

(0) Citizens should cover most expenses

in health care, children's education, etc.
(10) Crucial part of expenditures in health care, children's education etc. should be covered by the state. 


\section{[d] Flat tax}

(0) People with higher income should be subject to higher taxation.

\section{[g] European integration}

(0) European integration should be deepened

[n] Rent regulation

(0) State should regulate rents.

[o] Intervention in economy

(o) State should intervene into economy, in order to safeguard its effectiveness.
(10) All people should be subject to the same taxation, regardless of their income.

(10) European integration has gone too far

(10) State should not regulate rents

(10) In order to safeguard the effectiveness of economy, state should not take any interventions.

Note that the estimates of party cohesion differences between legislators and the median value for all members of a specific legislator's PPG. Median values are used as they are less influenced by outliers in the data than mean values. Nonetheless, using mean values yields similar results to those reported in Table 1. For all the issue variables it is expected that there should be positive coefficients in the regression models presented in Table 1 as difference from PPG in roll call voting is explained by difference from PPG in issue positions.

\section{Party norms variable}

Q. 10: Please, tell me to what extent do you agree with following statements (1 = strongly agree -11 = strongly disagree):

(a) In case there is an important law for the party, the deputy should vote in conformity with the parliamentary faction's resolution, even though it is against his/her opinion

(b) In case the deputy got into the parliament with a help of the presidency of the party, he/she should esteem the commitment to vote in conformity with the party, even though he/she does not agree with the bill

(c) In order to move up in the hierarchy of the Chamber of Deputies or his/her parliamentary faction, the deputy should support the major standpoint of the faction and party

(d) The deputy of the governmental party should from the principle vote in conformity with his/her faction's standpoint, whenever the majority of opposition deputies is against

(e) The deputy of the opposition party should from the principle vote in conformity with his/her faction's standpoint, whenever the majority of governmental deputies is against 
(f) The deputy of the governmental party should support the bills and governmental policies, because it is also support for the party

(g) In case the major standpoints of the party or the parliamentary faction disagree with the voters' opinion, the deputy should vote in conformity with the voters' opinion

(h) In case the standpoint of the presidency of the parliamentary faction is against the standpoint of the presidency of the party, the deputy should vote in conformity with the party's opinion

(i) The deputy of the governmental party should support the bills and governmental policies even though they are contrary to the platform of his/her party

Note that the 'Party norms' variable used in the OLS regression models in Table 1 is a summated rating scale (Cronbach alpha=.81) constructed using the responses for all nine items in this battery of questions. The logic of this party norms variable is that each of the nine items is an indicator of adherence to the social norm that a legislator should always support their party. Adherence to party norms should be negatively associated with not following the party line in roll-call voting.

\section{Conformity variable}

Q.6a Imagine a hypothetical situation: a minister of your party introduces a law to the parliament, but you have a different opinion on the topic. The faction does not declare mandatory voting. How would you vote?

Q.6b In another hypothetical situation, your political party supports a bill, which is also very important for the party, which is also very important in terms of the programme, but you have a different opinion on the topic. The faction does not declare mandatory voting. How would you vote?

Q.6c In another hypothetical situation, your political party supports a bill, which is also very important in terms of the programme, but you have a different opinion on the topic. The faction declares mandatory voting. How would you vote?

Q.6d In the last hypothetical situation, your political party supports a very important bill or vote (e.g. the law on budget, crucial transformation of taxes or confidence vote), but you have a different opinion on the topic. The faction declares a strictly mandatory voting. How would you vote?

Note that the response options in all cases were: 1) In conformity with my own opinion, 2) In conformity with the parliamentary faction's resolution. Here it is possible to use the responses from these four items to construct either a simple 
count measure of conformity or an ordinal measure. With a simple count scale each item is assumed to be equally important in indicating conformity. In contrast, the ordinal scale contends that avoiding conformity is easiest in the scenario outlined in Q.6a and becomes progressively more difficult until it reaches a maximum with Q.6d. Thus, a respondent who votes in conformity with their PPG in all scenarios regardless of difficulty is more conformist than a legislator who votes on their basis of their 'own opinion' (or ideal point) whenever possible. Adoption of a simple count or ordinal scale depends on how legislators answered this set of questions. Implementation of both scale types in the regression models reported in Table 1 reveal that both scales exhibit substantively similar relationships with the dependent variables. Consequently, only results for the simple count scale are reported, as the more sophisticated ordinal scale does not provide a better explanation of party discipline. Conformity to party leaders' wishes should be negatively associated with not following the party line in roll-call voting.

\section{Sanctions variable}

Q.7a Coming back to the hypothetical situations, we would like to know the probability of potential sanctions for voting against the parliamentary faction's resolution. In the first hypothetical situation, a minister of your party introduces a law in the Parliament, but you have a different opinion on the topic. The faction does not declare mandatory voting. What would be the probability of sanctions mentioned below?

Q.7b In the following hypothetical situation, your political party supports a bill, which is also very important for the party, which is also very important in terms of the programme, but you have a different opinion on the topic. The faction does not declare the mandatory voting. What would be the probability of sanctions mentioned below?

Q.7C The faction declares a strictly mandatory voting. What would be the probability of sanctions mentioned below?

Q.7d In the last hypothetical situation, your political party supports a very important bill or vote (e.g. the law on budget, crucial transformation of taxes or confidence vote), but you have a different opinion on the topic. The faction declares a strictly mandatory voting. What would be the probability of sanctions mentioned below?

(Response options: five-point scale, where ' 1 ' indicated very probable, and ' 5 ' not probable)

- I would be expelled from the party

- I would be expelled from the parliamentary faction

- I would not get on an elective position in the next elections 
- I would loose a good position in the parliamentary faction or committee on the first occasion

- In the future, the party would not support my nomination into the committee I prefer

- I will be given a warning

- Nothing would happen

Notes: This perception of the discipline variable results in a large amount of data (28 responses) for each legislator. This extensive set of responses was reduced by assuming that the most probable response for each of the seven consequences represented the respondents evaluation of what was most likely to happen in each of the four scenarios outlined. Where there were equal probability ratings for different consequences, the least stringent consequence was coded as the most probably evaluation. If respondents gave equal probability ratings for all consequences, then this respondent was excluded from analysis as their responses provide no information on their evaluation of likely consequences regarding the four scenarios examined. In the regression models presented in Table 1 it is expected that where legislators attach highest probability to serious consequences this will be negatively associated with deviation from (roll call) voting the party line. This is because the sanctions for breaking party discipline are coded in the parliamentary survey in descending order of seriousness.

\section{Control variables}

The 'experience' measure reflects how many occasions a legislator has been a member of parliament since 1986 and is a count variable. Within the survey dataset this variable has a maximum value of six and a minimum of one.

The 'age' variable contains four categories: 1) 18-40 years [10\%], 2) 41-50 years [24\%], 3) 51-60 years [33\%], and 4) 61 years or older [7\%].

For both the parliamentary experience and age variables, which are not strongly correlated $(\mathrm{r}=.20, \mathrm{p}=.03)$, it is expected that these variables will be negatively related to deviation from the party line in roll-call voting because long-standing position in the parliament is associated with strong links with a party.

There are five dummy variables for membership of each of PPGs. In the regression models membership of SZ (Green Party) is used as the base category. In the regression models the party dummy variables are included to avoid omitted variable bias and capture effects not measured by the party cohesion, party discipline, parliamentary experience, and age variables. Positive coefficients indicate membership of a specific PPG increases ceteris paribus deviation from the party line in roll-call voting for (unspecified) reasons particular to the party, and vice versa for parameters with negative signs. 


\section{Appendix III}

\section{Summary statistics for the dependent variables}

\begin{tabular}{lcccccc}
\hline Variable & Mean & Std err & Median & Variance & Skewness & Kurtosis \\
\hline W-NOMINATE dim 1 & .025 & .004 & .015 & .002 & 8.265 & 83.555 \\
Optimal classification dim 1 & .040 & .003 & .034 & .001 & 2.164 & 9.095 \\
IDEAL dim 1 & .028 & .006 & .014 & .004 & 8.361 & 82.417 \\
W-NOMINATE dim 2 & .126 & .011 & .082 & .016 & 1.503 & 1.825 \\
Optimal classification dim 2 & .580 & .025 & .604 & .087 & -.904 & -.376 \\
IDEAL dim 2 & .026 & .006 & .016 & .005 & 1.258 & 113.162 \\
\hline
\end{tabular}

Note that all dependent variables employed in the OLS regression models reported in Table 1 were transformed using the natural logarithm to attenuate the problems associated with skewness and kurtosis evident in this table. The transformed dependent variables were generally normally distributed except in the case of the optimal classification dependent variable for dimension 2 which exhibits bimodality. For the sake of having consistent dependent variables across all models reported in Table 1 were operationalised in the same manner. Alternative transformations of the optimal classification dim 2 variable yielded similar results. As the natural logarithm of zero is not defined observations that did not differ from the PPG median (i.e. had a score of zero) were given a small positive value (.001) so that the transformation procedure would not produce additional missing cases. This coding should have minimal impact on the substantive OLS regression results.

Source: Department of Informatics, Office of the Chamber of Deputies, Parliament of the Czech Republic and Survey of the Members of the Chambers of Deputies, 2007/2008, Department of Political Sociology, Institute of Sociology AS CR (authors' calculations). 
Summary statistics for the independent variables

\begin{tabular}{|c|c|c|c|c|c|c|c|c|}
\hline Variables & Mean & Std err & Median & Variance & Skewness & Kurtosis & Min & Max \\
\hline \multicolumn{9}{|l|}{ Cohesion } \\
\hline $\begin{array}{l}\text { Left-right } \\
\text { position }\end{array}$ & .905 & .143 & 1.000 & 1.511 & 3.640 & 17.957 & 0 & 8 \\
\hline $\begin{array}{l}\text { European } \\
\text { integration }\end{array}$ & 1.554 & .225 & 1.000 & 3.730 & 1.469 & 2.381 & 0 & 9 \\
\hline $\begin{array}{l}\text { Health } \\
\text { spending }\end{array}$ & 1.149 & .182 & 1.000 & 2.457 & 2.532 & 7.449 & 0 & 8 \\
\hline Flat tax & 1.189 & .241 & .500 & 4.292 & 2.893 & 8.839 & 0 & 10 \\
\hline $\begin{array}{l}\text { Rent } \\
\text { regulation }\end{array}$ & 1.500 & .242 & 1.000 & 4.336 & 2.166 & 4.928 & 0 & 9 \\
\hline $\begin{array}{l}\text { Intervention } \\
\text { in economy }\end{array}$ & .959 & .189 & .000 & 2.642 & 2.840 & 9.467 & 0 & 9 \\
\hline Party norms & 37.216 & 1.787 & 39.000 & 236.254 & .296 & .200 & 6 & 75 \\
\hline \multicolumn{9}{|l|}{ Discipline } \\
\hline Conformity & 2.486 & .095 & 2.000 & .664 & -1.301 & .335 & 0 & 4 \\
\hline Sanctions 1 & 6.095 & .154 & 7.000 & 1.758 & -1.301 & .335 & 3 & 7 \\
\hline Sanctions 2 & 5.932 & .163 & 6.500 & 1.954 & -1.299 & 1.074 & 1 & 7 \\
\hline Sanctions 3 & 5.014 & .169 & 6.000 & 2.123 & -.543 & -.734 & 1 & 7 \\
\hline Sanctions 4 & 4.662 & .179 & 5.000 & 2.364 & -.431 & -.808 & 1 & 7 \\
\hline \multicolumn{9}{|l|}{ Controls } \\
\hline Experience & 1.878 & .119 & 2.000 & 2.364 & 1.445 & 2.694 & 1 & 6 \\
\hline Age (years) & 50.390 & .768 & 51.000 & 8.299 & -.185 & .337 & 26 & 78 \\
\hline
\end{tabular}

Note that issue scale variables represent the difference between legislators' personal scores and their perception of their PPG's (median) position on the same scale. These issue distances are generally quite small, i.e. 1 point or less on a scale that has a maximum of 11 points $(0-10)$.

Source: Department of Informatics, Office of the Chamber of Deputies, Parliament of the Czech Republic and Survey of the Members of the Chambers of Deputies, 2007/2008,

Department of Political Sociology, Institute of Sociology AS CR (authors' calculations). 


\section{Correlation matrix for the dependent variables}

\begin{tabular}{|c|c|c|c|c|c|c|}
\hline Roll call measure by dimension(s) & $\begin{array}{l}\sigma_{1} \\
\tilde{\sigma}^{\prime} \\
3\end{array}$ & $\begin{array}{l}\bar{\tau}_{1} \\
y_{0}^{\prime}\end{array}$ & $\begin{array}{l}\vec{\sigma}_{1} \\
\underset{.}{\sigma}\end{array}$ & 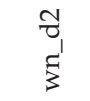 & $\begin{array}{l}\text { ગ્ } \\
\text { ర్ }\end{array}$ & $\begin{array}{l}\tilde{D}^{\prime} \\
\tilde{\sigma}^{\prime}\end{array}$ \\
\hline W-NOMINATE dim 1 (wn_d1) & 1.000 & & & & & \\
\hline \multirow[t]{2}{*}{ Optimal classification dim 1 (oc_d1) } & .637 & 1.000 & & & & \\
\hline & $<.001$ & & & & & \\
\hline \multirow[t]{2}{*}{ IDEAL dim 1 (id_d1) } & .093 & .136 & 1.000 & & & \\
\hline & .280 & .114 & & & & \\
\hline \multirow[t]{2}{*}{ W-NOMINATE dim 2 (wn_d2) } & .321 & .283 & .154 & 1.000 & & \\
\hline & $<.001$ & .001 & .073 & & & \\
\hline \multirow[t]{2}{*}{ Optimal classification dim 2 (oc_d2) } & .035 & .202 & -.026 & .257 & 1.000 & \\
\hline & .685 & .018 & .761 & .003 & & \\
\hline \multirow[t]{2}{*}{ IDEAL dim 2 (id_d2) } & .077 & .137 & .427 & .295 & .053 & 1.000 \\
\hline & .371 & .112 & $<.001$ & $<.001$ & .542 & \\
\hline
\end{tabular}

Notes: Correlation coefficients are Pearson Product moment estimates. All estimates in bold are significant at $\mathrm{p} \leq .10$.

Source: Department of Informatics, Office of the Chamber of Deputies, Parliament of the Czech Republic and Survey of the Members of the Chambers of Deputies, 2007/2008, Department of Political Sociology, Institute of Sociology AS CR (authors' calculations). 